showing, not only in the case of the mastoid but also in the form of the auditory meatus and middle ear, characters which in modern man occur only in newborn infants and very young children-a widely open meatus terminating at an ear drum the inclination of which closely approaches the horizontal. This state of affairs is lost in Homo sapiens long before the age of puberty is attained. As Dr. Black remarks, the features of the tympanic region of Sinanthropus are admirably suited to serve as a starting-point for phylogenetic speculation. "With this generalised type before us it is not difficult to imagine developmental stages through which such an element in a stem-form may well have passed, leading to the modifications such as are characteristic of the Piltdown, Neanderthal, and modern men ". On the other hand, since all the essentials of the tympanic morphology of the great anthropoid apes may be recognised in these elements of Sinanthropus, a comparison of the latter may serve to indicate in some measure the degree of their divergence from a common type. In spite of this provocative comment, Prof. Davidson Black refrains from discussing the intriguing problems he mentions. He does not depart from the admirable restraint that characterises all he has written upon this subject, which makes his monograph a reliable guide to those who want the data and prefer to form their own opinions as to their meaning.

The great importance of the discoveries in China lies in the fact, not only that the material is more abundant than the remains found at Trinil and Piltdown, and their geological age is unquestionable, but also that, while Sinanthropus is differentiated from the genera Pithecanthropus and Eoanthropus, it is much more generalised than either, yet definitely linked to both. While it is the most primitive type of human being so far discovered, its structural affinities with both the Javanese and the British genera link together all the known types of Pleistocene men and give cohesion to our knowledge.

It is fortunate that the information concerning this unique material has been so fully and so promptly supplied to anthropologists in a monograph which is distinguished by admirable clearness and impartiality. Once more Prof. Davidson Black deserves our congratulations on a great achievement.

\title{
The Spicer-Dufay Process of Natural Colour Kinematography.
}

\section{By T. Thorne BAKer.}

LL modern attempts to reproduce by photoA graphy the natural colours of a subject depend upon some method of three-colour analysis. The theory that by the admixture, in various proportions, of blue-violet, green, and orange, any colour in Nature can be imitated, has been adequately borne out by practical experiment. Socalled 'two-colour' processes must at the best be regarded as crude attempts to saddle each of two of the primaries with one-half of the third.

Methods of photography in which a glass support is coated with a mosaic or matrix of tiny coloured areas of the three primary colours, and then with a photographic emulsion, are well-known. Such material is exposed through the coloured mosaic, so that the light rays are microscopically analysed before reaching the sensitive emulsion. It is then developed, and after the black developed image has been dissolved away, the previously unexposed silver salts are exposed to light and themselves developed and blackened in turn. This procedure gives a positive transparency image, and if it be viewed by transmitted light - that is, through the coloured matrix on which it lies-the original picture will be seen in its original colours. 'To $\Lambda$. and $L$. Lumière belongs the credit of having first issued such a material (1907); it is still known as the Autochrome plate, and is still largely used.

Motion picture photography based on the same fundamental idea has proved vastly more complicated. The coloured mosaic necessarily absorbs a very high proportion of the incident light, and corresponding increase in exposure is required. With the advent of 'talking pictures', the old speed of sixteen pictures per second in kinemato- graphy has been raised to twenty-four, and with the best shutter mechanism this means that no more than 1/40 second can be allowed for each individual exposure. Hence quite apart from the immense improvement in large aperture lenses which has come about in recent years, it has been necessary to produce panchromatic emulsions of extremely high sensitivity.

The films exhibited on May 20 at the conversazione of the Royal Society at Burlington House were procured on a new film which has been developed during the past four years in the research factory of Messrs. Spicers, Ltd., at Sawston, Cambridgeshire. The film base itself, which is made at Sawston, is of the acetate type, and is non-inflammable in the strictest sense. By a combination of new plasticisers with a novel method of maturation, a film has been produced which retains its suppleness and whiteness indefinitely. So rapid is the maturing that the base can be used for photographic purposes a few hours after it has been cast.

The base is coated with a very thin layer of collodion containing a green dye of the necessary concentration to act as a primary green filter. It is then passed through a rotary printing-press of special design which impresses upon it 375 parallel ink lines to the inch, with the same number of intervening clear spaces. It is next passed over rollers through a bleaching bath, which decolorises the green dye where it is unprotected by the greasy lines of printing-ink. It then passes through an orange dye, when the bleached spaces become dyed the primary orange. Finally, passage through a series of benzole tanks against revolving brushes removes the printing-ink, and a material is left

No. 3213 , VoL. 127] 
stained with alternate green and orange lines, 375 of each to the inch. A second, similar, procedure, with the greasy lines printed at right angles, provides the third primary, blue-violet, and in this way a mosaic of more than half a million blue-violet, green, and orange rectangular areas is formed on the surface of the film base.

The colour mosaic is next coated with two protective layers, in order to prevent any desensitising effect of the matrix colours upon the sensitive emulsion. A panchromatic emulsion of very high speed is finally applied. The whole procedure is carried out on $1000-\mathrm{ft}$. lengths of film 21 inches wide, which are slit up into fifteen 'cuts' of standard kinematograph width, $35 \mathrm{~mm}$. A very simple protective device makes it possible to leave a colourless sound track, one-tenth of an inch wide, in each cut, so that the recording of sound with colour can be readily achieved.

Careful control of the coating of the first layer of green collodion has resulted in the production of a matrix of very uniform balance, which has been found indispensable in order that, in the subsequent dyeing processes, a correct balance of spectral distribution is maintained. It is interesting to note that the theoretical primaries have been largely departed from, and that the overlaps in the spectra of the blue, green, and orange regions greatly exceed those usually agreed upon amongst three-colour workers. That this has been justified is shown by the extraordinary faithfulness of the colour rendering.

The negative film, after reversal and redevelopment, becomes converted, as already stated, into a positive picture, which can be immediately thrown upon the screen. Such an original or 'master' positive would be of little value were it not possible to make an unlimited number of copies. The copying of any form of geometrical pattern has hitherto involved the appearance in the print of diffraction patterns or moiré, and this has greatly militated against attempts at the commercial application of matrix processes.

Satisfactory duplication of the Spicer-Dufay pictures has been effected by a comparatively simple expedient. The coloured original is passed through the gate of the printing-machine, and an image of it is thrown by projection upon the copying film, which is synchronously moved forward. The lens has been so designed that it will focus critically the black silver image of the master copy upon the sensitive film of the copying material, while the coloured matrix, which is separated from the image by about $10 \mu$, is slightly blurred or diffused. In this way very exact natural colour copies can be obtained, which are printed at the standard rate of 800 pictures a minute. The ease of duplication at once places the process on a practical basis, for which there will doubtless be many scientific uses, apart from popular entertainment.

\section{Centenary of David Edward Hughes.}

$\mathrm{T}^{\mathrm{o}}$ commemorate the centenary of the birth of David Edward Hughes, whom Sir Joseph Larmor, in 1900, described as " one of the great scientific inventors of the age ", an address on his life and work was given by Mr. Sydney Evershed, on May 14, to the Institution of Electrical Engineers, a society of which Hughes was president in 1886 .

Born in London on May 16, 1831, Hughes was the son of a Welsh bootmaker, who in $1838 \mathrm{emi}$. grated to the United States and settled in Virginia. At the age of nineteen he was appointed professor of music in St. Joseph's College, Bardstown, Kentucky, and while there gave lectures on natural philosophy. Like many others, he became interested in the rapidly spreading electric telegraphs and in 1854 made a practical type-printing telegraph. Resigning his professorship, in 1857 he returned to Europe to exploit his invention.

In the course of the next twenty years, Hughes made a fortune and, taking up his residence in London, devoted himself to scientific research, the first fruits of which was the invention of the microphone. He retained all his life the title of professor and his American citizenship. In 1880 he was elected a fellow of the Royal Society, in 1885 he was awarded a Royal Medal, in 1891 he became a vice-president of the Royal Institution, and in 1896, four years after Edison, was awarded the Albert Medal of the Royal Society of Arts. He died from influenza, at his house, 40 Langham Street, on Jan. 22, 1900, and was buried in Highgate
Cemetery. After his death his widow returned to the United States, where she died about ten years ago. She had given his note-books to the British Museum, but much of his apparatus was left in a furniture store near the Tottenham Court Road, where it lay unheeded until 1922. Through the action of the late Mr. Campbell Swinton, much of the apparatus was secured for the Science Museum, where it can be seen. Hughes left a fortune of some $£ 470,000$. Of this he bequeathed about $£ 13,000$ to the Institution of Electrical Engineers, the Royal Society, the Paris Academy of Sciences, and other bodies, but the greater part went to the Middlesex, London, King's College, and Charing Cross Hospitals.

Many of these facts were referred to by $\mathrm{Mr}$. Evershed in the course of his interesting address, the main part of which, however, was devoted to a consideration of the two outstanding achievements of Hughes's life ; the invention in his early years of the synchronous type-printing telegraph, and then, in later life, the discovery of the micro. phone. "In these his genius was at its height, and, to use an engineering metaphor, it is the peak values that count when we attempt to estimate genius."

In the middle of the last century, said $\mathrm{Mr}$. Evershed, electric telegraphy was undergoing rapid development. In England we were using Wheatstone's needle instruments ; in America, Morse had produced his ink writer and efforts were being made to make instruments print messages in plain type. 